\title{
Primary Exploration on the Differentiation of the Animation Industry Models of China, Japan and America in the Context of the Two-dimensional Culture
}

\author{
Peng Sun \\ Dalian University of Science and Technology \\ Dalian, China
}

\begin{abstract}
In recent years, the term "two-dimensional culture" has been mentioned by more and more people around the world. The two-dimensional culture has gradually penetrated into our daily lives. People often confuse the twodimension with ACGN, but the two-dimensional culture is essentially different from the two-dimension and ACGN. In the context of the two-dimensional culture, the animation-related industries of various countries are exploring their own development models. The Japanese model relies on screening out the popular anime works for commercial operations. The American model relies on the investment of time and money by several big anime giants. As an emerging economy, the Chinese model is to use the Japanese business model or the American elite model as a template, or to explore an animation industry model with Chinese characteristics, which requires constant efforts of several generations to explore. Based on the current development of China's animation-related industries, this paper finds that China needs to explore a contemporary animation industry model with Chinese characteristics by comparing the animation modes of China, Japan and the United States.
\end{abstract}

Keywords-two-dimension; ACGN; animation industry; animation

\section{INTRODUCTION}

From the end of the 20th century to the present, the animation industry has flourished around the world. In recent years, words such as two-dimension, ACGN and etc. have been widely used in real-life scenarios. This is a reflection of the booming animation industry. In the world, the two major animation countries, Japan and the United States, already have their own animation industry models, and they have all matured. For historical reasons, China's animation industry has been stagnant for some time in the middle of the last century. However, began in the 1980s and been paid attention to at the beginning of this century, China's animation industry is gradually exploring the Chinese model with Chinese characteristics. By comparing with the Japanese and American models, and analyzing the problems encountered by the Chinese animation industry in recent years, this article believes that Chinese animation is not much different in the level of technology, but its gap in the operation of the animation industry with Japan and the United States is huge. The Chinese animation industry needs a mature commercial operation model to support it.

\section{PRELIMINARY STUDY ON TWO-DIMENSION AND ACGN}

The two-dimension is derived from the Japanese "にじげ $\llcorner "$. It has two meanings. On the one hand, it refers to the virtual two-dimensional space. On the other hand, among Japanese animation enthusiasts, it refers to characters in works such as animations and games. [1]

There is a correlation between the two-dimension and ACGN. In the definition of the public, the two-dimension and ACGN are often confused. ACGN is short for Animation, Comic, Game, Novel, and sometimes called ACGNC, where the last $\mathrm{C}$ stands for Cosplay. The twodimension usually contain ACG without $\mathrm{N}$ (Novel), but ACGN is often in the range of the two-dimension.

The two-dimension emphasize the difference from other dimensions. In the anime language, one dimension refers to the world of novels, the two-dimension refer to the world of animation, and the three dimensions refer to the real world. The four dimensions refer to the four-dimensional space, to which the time can be added, such as the four-dimensional pocket of Doraemon. There are even other multidimensional spaces such as five dimensions. ACGN emphasizes forms and carriers, such as novels, comics, animations, and games, which are in paper or digital form. The public often confuses the two-dimension with ACGN because of the context and environment in which they are expressed. Therefore, understanding the context of the two-dimension and ACGN can help the public understand the difference between them.

"Two-dimension" and ACGN, these two terms are widely spread around the world. Although they have different directivity and differentiation when used in context, it can also be seen that animation-related industries are booming in the world, which is inseparable from the two- 
dimensional culture and the animation industry model of each state.

\section{JAPANESE AND AMERICAN ANIMATION MODES UNDER THE BACKGROUND OF THE TWO-DIMENSIONAL Culture}

\section{A. Two-dimension and Two-dimensional Culture}

In recent years, with the gradual emphasis on intellectual property, China's domestic IP industry has experienced explosive growth patterns, and its development is inseparable from the two-dimension.

The two-dimension is different from the two-dimensional culture. The two-dimensional culture is a consumption trend of derivatives of intellectual property which is especially centered on the characters such as ACG. Therefore, it can be said that the popular nature of the two-dimensional culture is the prosperity of the animation culture industry. The animation culture industry will ultimately be reflected in commercial profits, and only the animation powers Japan and the United States will be able to achieve the ultimate in the animation industry.

\section{B. Differentiation of Japanese and American Models}

In the world, many anime fans can easily call out a Japanese cartoonist's name or anime works, and the cartoonist's popularity is much higher than the studio's reputation. For examples: Miyazaki Hayao and his "Spirited Away", Kon Satoshi's "Millennium Actress", Makoto Shinkai's "Your Name", Eiichiro Oda's "One Piece", Gosho Aoyama's "Detective Conan", Masami Kurumada's "Saint Seiya", Fujiko F. Fujio's "Doraemon", and so on, too numerous to mention one by one. However, when you talk about so many Japanese cartoonists and anime works, you will find that there are very few anime fans around the world, who can called out the names of American cartoonists, but when it comes to American Disney, Pixar, DC, Marvel, these animation companies, everyone is familiar with them. This is the embodiment of the differentiation of Japanese and American animation industry models.

\section{Japanese Business Model}

In the current animation industry, Japan's business model and the US elite model are the most famous. The animation industry both in Japan and the United States is divided into four processes. According to the statistics of the Ministry of Economy, Trade and Industry, $87 \%$ of Japanese people like anime, and $84 \%$ have animation-related products.

In Japan, many cartoonists first have to submit to the animation magazine (such as Shonen JUMP), the editors of the comic magazine editors, and eliminate those works that are not enough in various aspects such as technology and scripts. Finally, only some of the works can be serialized in the comic magazine. Through the tracking of praise and popularity of serials, the comic magazine will choose the most popular serial comics to issue a separate edition, and then the single book will be made into a cartoon for broadcast, and finally the animation derivative will be developed and applied to business. The whole link is interlocking. Through the pyramidal layer screening, select the excellent animation works of the pyramids for commercial operation, as shown in "Fig.1":

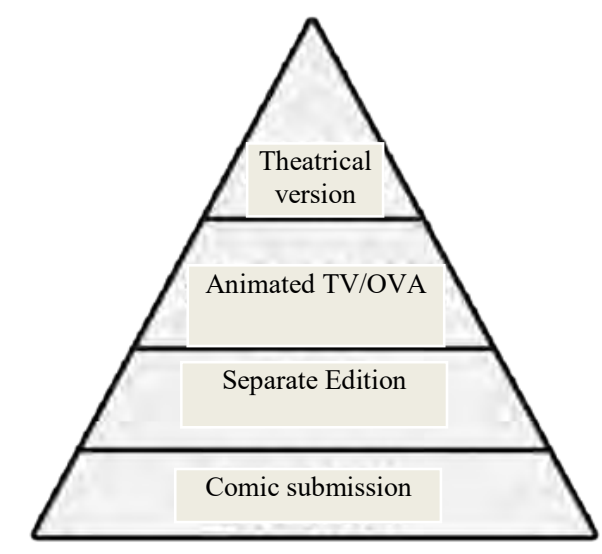

Fig. 1. Japan's animation business model.

The Japanese model is a business model that s oriented by the popularity of anime enthusiasts and practitioners, and is ultimately driven to the audience through industrialization and commercialization processes. The entire production is linked to the business. The popularity of scripts and comics can make an unknown comic enthusiast or practitioner famous within a few years. In terms of derivatives, such as game IP, the current (2018 data)widely concerned such as "Naruto", "One Piece" and other first-line strong IPs' prices have reached a guaranteed 8 million, plus an additional 5\% from the PC, $8 \%$ from Mobile.

\section{American Elite Model}

Compared to the Japanese business model, the US model is very different. The American model is based on the industrialization of the script. A large number of script writers write the script, and then perform the follow-up creation after the script reviewer finishes the touch. This model is especially prominent in the mode of the giant comic companies such as Marvel and DC. At the same time, the animation film production time cycle in the United States is relatively long, and the technical and detail requirements are kept improving. Take "Coco" as an example. The total length of the film is 105 minutes. Their key personnel have been visited to Mexico for 5 times to find a perfect view. The film takes around 7 years in total and the total investment is more than 200 million US dollars.

Compared to the Japanese business model, the American elite model relies more on copyright revenue. In 1999, Marvel sold Spider-Man copyright to Sony Pictures for $\$ 7$ million. Marvel earned a large amount of copyright fees by buying and selling IP copyrights. From 2008 to 2017, Marvel has already owned 15 films, and the global revenue of these works has exceeded 10 billion US dollars, of which billions 
of dollars of revenue comes from the copyright license of toys, goods and perfumes.

Whether the model is successful or not, currently it is only on halfway, only the subsequent derivatives and the industrial and consumption upgrades around IP are the touchstones for measuring the success of the model establishment.

\section{E. Difference Between Japanese and American Animations}

- Difference between the plots. Japan and the United States are not only differentiated in terms of patterns, but also have distinct differences in the content of animated stories. Japanese animation focuses on storytelling and the sentiments behind the story. Its content is extensive, involving anti-war, environmental protection, friendship, love, family, etc., and the content expressed is not deliberate. For example, the "Princess Mononoke", animated by Miyazaki, is about the relationship between man and nature. The theme of "The Wind Rises" is anti-war, and "Castle in the Sky" tells the story of fighting for dreams. The "Spirited Away" is about the relationship between people and society, between people and nature. For American animation, with the works from DreamWorks Studios, Pixar, and Disney as examples, "Frozen" is about adventure, "Zootopia" is about dreams, and "Coco" is also about dreams.

- Narrative way. The narrative style of Japanese animation has a large time span, which often travels through the time and has a combination of present and future, present and past. The story of American animation is often narrated in a cheerful rhythm with a good love, and its time span is small.

- Character modeling and scenes. Compared with American animation, the narrative method of Japanese animation is closer to the movie, and the characters and scenes are closer to reality, which rarely involves the exaggeration and deformation of the characters, while American animation emphasizes the exaggeration and distortion of characters.

- Production method. Japanese animation is mostly based on two-dimensional hand-drawn and paper-free animation, which pays more attention to the expression of the story and the artistry of the picture. American animation is mostly based on 3D animation, which highlights the grandeur of the scene and the advanced technology.

\section{THE TRANSFORMATION OF DOMESTIC 2D}

\section{ANIMATION UNDER THE TWO-DIMENSIONAL CULTURE}

At the beginning of the 21st century, the development of domestic animation was relatively rapid, and since 2010 , with the support of policies, it has ushered in a small golden cycle. The total number of minutes of domestic cartoons shows an explosive growth each year, which is mainly due to policy support. The state subsidizes $2 \mathrm{D}$ and $3 \mathrm{D}$ animation according to the length of the broadcast. However, due to the profit-seeking thinking, many animation production companies aim only to defraud subsidies and quickly gather wealth, and do not make animation production as a longterm cultural industry. Therefore, behind a large number of minutes, there are many problems of plagiarism and rotten tablets. In the four years from 2010 to 2013, the duration of domestically produced cartoons is more than 200,000 minutes per year. If one episode is 40 minutes, it is more than 5,000 episodes, as shown in "Table I".

TABLE I. NATIONAL TV ANIMATION PRODUCTION AND DISTRIBUTION (2010 TO 2016)

\begin{tabular}{|c|l|l|l|l|l|l|l|}
\hline Year & 2010 & 2011 & 2012 & 2013 & 2014 & 2015 & 2016 \\
\hline Number & 385 & 435 & 395 & 358 & 278 & 275 & 261 \\
\hline Minutes & $\begin{array}{l}2205 \\
30\end{array}$ & $\begin{array}{l}2612 \\
24\end{array}$ & $\begin{array}{l}2229 \\
38\end{array}$ & $\begin{array}{l}2047 \\
31.5\end{array}$ & $\begin{array}{l}1385 \\
79\end{array}$ & $\begin{array}{l}1382 \\
73\end{array}$ & $\begin{array}{l}12505 \\
3\end{array}$ \\
\hline
\end{tabular}

Beginning in 2014, with the emergence of plagiarism and rotten films, the state has increased the requirements for some policies, which led to the elimination of some lowquality animation companies in the process of industrial transformation. At the same time, due to the popularity of the animation industry in the past few years, many schools that do not have the strength of software and hardware have opened animation major, which has led to over-expansion of animation talents in some areas. This is one reason why the animation became a red sign university major in those years. However, since 2014, the entire animation industry has undergone a massive shakeout. Some unpowered or unprofessional companies have been eliminated or voluntarily withdrawn, and the entire animation industry has gradually begun to recover and transform after experiencing a cliff-like collapse around 2014.

Since 2016, the IP industry has gradually become more and more popular. Taking domestic cartoons as an example, the derivative products of the well-known "Radiant and Wolf" have penetrated into people's lives. After the "Little Pig Peggy", a foreign cartoon, became popular, its various cartoon derivatives have occupied the top spot in the list of hot-selling goods in various luxury stores. In terms of comics, the long-running comic book "Rakshasa Street", which ranks first on www.u17.com, was filmed as a live-action movie. The same is true of the Japanese comics "Attack on Titan". In addition, the comics, TV series, and movies, which were based on the novel "Time Raiders", were sought after by many tomb fans when it first came out. In terms of games, examples of game-related peripheral products are numerous.

At present, domestic animation and animated films have already had a certain pattern. In terms of comics, the manga submission system token the Internet APP as the carrier has gradually formed, such as the www.u17.com, Tencent comics, NetEase comics and so on. "Rakshasa Street" is a typical Japanese business model, which develops from comics to TV dramas to live-action editions, similar to the "Uncharted Walker", "Please take my brother away" and other popular anime. Elite models such as "Monkey King: Hero is Back", "Da Hu Fa", "One Hundred Thousand Bad Jokes II", "Big Fish \& Begonia", etc., which have large 
investment and take a relative long time, are also emerging. The film, "Monkey King: Hero is Back", took 8 years for brewing and 3 years for produce. The "Big Fish \& Begonia" took 3 years to complete, and the 6-person team took 3 years to complete the "Da $\mathrm{Hu} \mathrm{Fa".}$

\section{CONCLUSION}

Neither the Japanese business model nor the American elite model succeeded in one day. In the early 20th century, Chinese, Japanese and American animations were at the same level of development. Disney's commercialization model has made today's big-name animation companies such as Disney, DreamWorks and Pixar.

Chinese animation is represented by the Wan Brothers, and the early Chinese animations inspired by Chinese traditional opera and Peking Opera are recognized worldwide. Many water-ink cartoons represented by Shanghai Animation Film Studios also received international acclaim in the 1960s and created a precedent for Chinese ink animation.

After more than 20 years of development, the Japanese animation which began to develop in the 1920 s and rose in the $1960 \mathrm{~s}$ entered the golden age in the 1880s. The development of Chinese animation, which began in the mid1960 s and stagnated in the late 1980s, gradually thawed with the introduction of a large number of foreign cartoons after the reform and opening up.

In the 1980s and 1990s, there were many Chinese and foreign co-animated cartoons, such as the "The Story of Panda-Taotao" and "Bu She Zhi She" co-produced by China and Japan in the 80s, the "Little Mouse on the Prairie" coproduced by China and America in the 90s, etc. The real recovery of Chinese animation began after 2000. From plagiarism to returning to traditional Chinese culture, Chinese animation is trying to achieve a corner overtaking. If the production level of Chinese animation develops at this rate, it will be greatly improved in the short term, but the animation-related marketing and operation and maintenance are still far from the mature operation of Japanese and American animation.

In summary, after 2000, the production level and ideas of Chinese animation gradually improved. After the completion of the animation, the IP and related industries produced by it are still far from that of Japan and the United States. On the one hand, in terms of animation production and long-term development, it needs policy support and the persistence of animators. On the other hand, in the follow-up marketing, it also needs a mature commercial operation mode to support.

\section{REFERENCES}

[1] Matsumura Akira. デジタル Daijisen. Japan: Shogakukan, 2018.4

[2] Research on the Operation Mode of Japanese Animation Industry On the Enlightenment to Chinese Animation Industry. He Jianping, Liu Jie.School of Communication, Shenzhen University.Contemporary Cinema. 2009(07). (in Chinese). 